\title{
The Impact of Online Communication on Learning English: A Case Study of Saudi EFL Learners
}

\author{
Bakr Bagash Mansour Al-Sofi \\ Department of English, College of Sciences and Arts, University of Bisha, PO Box \# 101, Al-Namas, 61977, Saudi Arabia \\ E-mail: bbmansour@ub.edu.sa
}

Received: 15-02-2016

Published: 01-07-2016
Accepted: 23-04-2016

doi:10.7575/aiac.ijalel.v.5n.4p.91
Advance Access Published: May 2016

URL: http://dx.doi.org/10.7575/aiac.ijalel.v.5n.4p.91

\begin{abstract}
This study examined the perceptions and views of Saudi undergraduate EFL learners regarding the role of online communication in improving their English, including the basic skills and the other aspects of language learning. It also aimed to identify the impact of some factors on the learners' perceptions on the role of online communication in developing their English level. This study is quantitatively designed in which a written questionnaire was used to collect the data of the study during the first semester of the academic year 2015-2016 from 171 randomly selected students who joined different levels in English Department, College of Sciences and Arts, University of Bisha, Saudi Arabia. For analyzing the data of the study, different statistical techniques in Statistical Package for Social Sciences (SPSS), 21.0 version were ran. The results indicated that the students had high positive perceptions of the significant role of online communication in fostering their English. Furthermore, it was found that there were statistically significant differences in the online communication scores for the factors of foreign friendship, university level, and the frequent use of the Internet. On the contrary, the results revealed that there were no statistically significant differences in the online communication scores for the other two factors of age and the frequent use of English online. Students are invited more than ever before to grasp every online chance for developing their English. In particular, they are required to employ online communication not only for socialization purposes, but for using it as an educational tool as well.
\end{abstract}

Keywords: Online communication, basic English skills, language learning aspects

1. Introduction

It is an indisputable fact that the frequent use of the Internet has crept into our everyday life in which we live in a rapidly changing communication setting. Actually, in addition to the classroom learning, there are other valuable opportunities for learning English such as face-to-face communication in non-learning contexts and online learning including social networking. To the best of the researcher's knowledge, these useful opportunities have not been appreciated enough and not given much attention in learning English in Saudi Arabia and hence deserve to be researched. The present study, therefore, tried to fill this gap. Precisely, it aimed to recognize the Saudi learners' perceptions of the role of online communication in improving their English, including the basic skills and the other aspects of language learning. This study was not about the general role of technology in language learning; rather it paid a special attention to the online communication (synchronous and asynchronous) as a learning platform rather than as a socialization means. Specifically, it provided a close insight into the informal out-of-class learning that occurs anywhere and anytime without the attendance of the teacher bearing in mind that it complements the formal in-class learning and the two can play an essential role in enhancing students' English.

As far as the researcher was concerned, discussing this issue of improving and practicing language level cannot be done in isolation from the other factors that affect language learning such as motivation, confidence and attitudes towards language learning and culture, etc. First, this study concentrated on the valuable role that online communication can play in developing the input and output language skills. In particular, reading and writing skills, for example, can be developed through blogs, forums, chatting, social networking, email writing, etc. On the other hand, listening and speaking skills can also be enhanced through authentic materials, and audio and videoconferencing in social networking in general. Second, when communicators virtually engage with others, they can develop the other aspects of language learning such as building their vocabulary, being more confident, increasing their motivation and positive attitudes towards others and their cultures, and decreasing language use anxiety.

According to Salmon (2011), "now, for many people, being online is a normal part of their everyday interactions" (p. 16). Using English for connecting and recognizing this world, the Internet has eliminated the geographical borders between countries, and has facilitated the communication between people from different cultures. O'Dowd (2007) states that "the internet and its associated communication tools have clearly become one of the main environments of expression, recreation and socialisation for members of affluent societies" (p. 20).

Chapelle (2003) highlighted that "in keeping with the common wisdom suggesting that if you want to learn English, you should go live in a place where English is spoken, many sites for communication among English learners through computer-mediated communication on the Internet offer opportunities for conversation with other English speakers" (p. 35). At this point, an attention can be paid to the easiness and availability of the Internet access anytime and anywhere. 
It motivates users to interact and engage easily all the time with anyone from all over the world. Similarly, O'Dowd (2007) believed that the "availability of high-speed internet connections and communication tools such as e-mail, chats, instant messaging, online telephony and videoconferencing allows people to socialise and communicate with colleagues, friends and family in ways and with a regularity never before thought possible" (p. 17). This clarifies that the easiness and accessibility of the Internet has accelerated the use of online communication not only for socialization, but also as a learning tool.

Taking into account the users' vastly different characteristics (such as culture, age, gender, educational level, economic status, language, and other dimensions) that would hinder communication in the physical world, the online settings have opened an amazing window for empowering them to improve their English performance, especially for women, lessmotivated, shy and/or undermined people, and those with high anxiety levels (Cassell \& Tversky, 2004; Lee, 2002; O'Dowd, 2007). According to O'Dowd (2007), "those who may feel uncomfortable about participating in face-to-face interaction or who may be discriminated against in such interaction will have an opportunity to participate more in online learning scenarios" (p. 25). This indicates that online communication is of great help especially for the younger generation who are more willing to use the Internet all the time.

From an educational perspective, the expected benefits of the use of the Internet are facilitating communication, helping users to develop their language skills, reducing stereotypes and prejudice, and enriching their knowledge of another culture, etc. Supporting this idea, Salmon (2011) illustrated that "working online should be viewed as a new context or environment for learning, not just as a tool. It enables individuals and groups of people to carry on conversations and discussion over the computer networks" (p. 16). Hence, it is believed that the online environment has become a valuable resource for language learning as it motivates the students to develop not only their language skills, but also their cultural awareness and understanding of others.

Nowadays, the unprecedented need to learn and master English is driven by its status as a lingua franca and its crucial importance in various fields and situations. In view of the fact that English is taught as a foreign language in Saudi Arabia and as the main objective of this study, the informal online learning opportunities were looked at as a necessary addition to or completion of the in-class learning for developing students' English levels, but never in place of it. In other words, employing the online communication for developing language is another option that paves the way for and meets the growing international demands. To sum up, Meier (2007) referred that terms such as 'e-learning', 'online learning', 'virtual learning', 'web-based learning', 'internet-based learning' and 'resource-based learning' all refer to the use of Internet technologies to provide education (p. 661). In this study, the reviewed literature used these terms interchangeably.

\section{Literature Review}

The Internet has changed the way people interact with each other. It has given them an open space to increase their learning outcomes, specially developing the language skills. As the main motive of this study, the online discussions are most prevalent and available nowadays for learning purposes. Liu, Chen, Sun, Wible, and Kuo (2010) highlighted that "online learning is becoming an increasingly important learning trend" (p. 601). Ware and Kramsch (2005) showed that in EFL realms, technology makes it possible to offer opportunities more commonly found only when there is a surrounding population of native speakers, and thus helps transform traditionally passive learners into more engaged and interactive learners. In the same way, Kabilan, Ahmad and Zainol Abidin (2010) confirmed that "learning does not necessarily mean learning in a formal setting, within a formal classroom and guided by an instructor; for instance, learning can also take place anywhere as long as there are meaningful interactions between learners that lead to knowledge construction" (p. 181). Similarly, Salmon (2011) pointed out that "working together, perhaps informally, in groups, for learning purposes is a tradition in many parts of the world" (p. 15). To illustrate this point, an appropriate use of online tools is a matter related to individual differences rather than a general contextual setting. Beliefs, knowledge, background, and experiences play an important role in using these tools either positively or negatively and in making users differ from one another.

Without doubt, the field of online learning environment is a concept of great relevance in the present day. It has been of special concern to many scholars and researchers (Kabilan, Ahmad \& Zainol Abidin, 2010; Kern, Ware \& Warschauer, 2004; Lee, 2002; O’Dowd, 2007; Pasfield-Neofitou, 2012; Ware \& Kramsch, 2005; Wu, Yen \& Marek, 2011). They affirmed that the online communication creates authentic learning settings. To begin with, O'Dowd (2007) brought to light that "the rise of the internet and online communication technologies over the past 15 years has undoubtedly changed the way people in more affluent parts of the world work, communicate, socialise and learn" (p. 17, italics added). Comparing online communication with face-to-face interaction, Lee (2002) clarified that "during the online negotiation, learners are exposed to input, feedback, and output in a way similar to what they would experience through face-to-face interaction. These exposures to input, output, attention to feedback, and linguistic form are essential to SLA" (p. 17). The different communication situations give communicators the chance to express and share their ideas and receive feedback responses immediately in real-life chats. Warschauer (2004) found that students used language which is "lexically and syntactically more formal and complex in electronic discussion than they did in face-to-face discussion, thus demonstrating another possible advantage of computer-mediated communication" (p. 7). Kabilan, Ahmad \& Zainol Abidin (2010) stated that the use of Facebook would enhance the students' communication skills, assist them to practice writing in English, make learning English more fun, and enhance their confidence to write in English. It was elicited that online communication has played a motivating role in enhancing the students' learning of English beyond the classroom environment and in creating a non-threatening space. Bearing the same opinion, PasfieldNeofitou (2012) pointed out that "CMC may provide a vehicle for students to not only have contact with native speakers (NSs) of their target language, but to also learn language outside of the classroom" (p. 1). 
Singhal (1998) reviewed several studies and projects on computer-mediated communication used for enhancing L2 learning and culture education, and examined their impact on elementary, secondary, and college students. She concluded that e-mail and teleconferencing provided authentic communication and fostered awareness of languages and cultures. Stepp-Greany (2002) conducted a study in the Spanish context to identify students' perceptions of the effects of technology on the foreign language learning experiences. The participants perceived that cultural knowledge, listening and reading skills, and independent learning skills were enhanced. Moreover, the participants gained confidence to direct their own learning.

More recently, Yang and Chen (2014) carried out a study in Taiwan for creating an authentic EFL classroom. This oneyear action study carried out three collaborative intercultural projects using web-based tools (online forums, weblogs, Skype, and email) in a $7^{\text {th }}$ grade EFL class. The students acknowledged that they improved their knowledge of the varieties of English language use and culture, improved their vocabulary, writing, and technological abilities, and learned collaboration. Moreover, the results revealed that the participants had strong positive attitudes towards technology-enhanced intercultural language learning (TEILI), which enabled the learners to experience authentic language learning that fostered linguistic competence and ICC. The findings also suggest that TEILI approximates reallife learning contexts by allowing students to use a language for the same purposes that they will use it outside school.

Online communication is a gateway that opens the doors for people to achieve the other aspects of language learning. That is to say, in addition to the prominent role of online communication in enhancing the input and output language skills, it has offered great potential for the development of the other aspects of language learning. These aspects include building the learners' vocabulary, being more self-confident, increasing their motivation and positive attitudes towards others and their cultures, and decreasing language use anxiety. In this sense, O'Dowd (2007) stated that online interaction can "increase intercultural sensitivity and to encourage learner independence" (p. 4). Besides, Swaffar (1998) concluded that online exchange helps FL students to "engage more frequently, with greater confidence, and with greater enthusiasm in the communicative process than is characteristic for similar students in oral classrooms" (as cited in Lee, 2002, p. 17). Moreover, he confirmed that this opportunity prepares learners "for the complex yet enriching experience of foreign language and culture learning" (p. 3). Zeiss and Isabelli-Garcia (2005) stated that CMC may have a more positive effect on the acquisition of students' cultural awareness that engage in CMC than on those who do not. CMC is most effective for increasing awareness about the topic of current events, followed by daily life and educational systems. As intercultural competence is now a necessity rather than an option, O'Dowd (2007) referred that learners can develop their communicative competence as they "are exposed to authentic input in the target language from their partners and they are free to express themselves away from the watchful gaze of their classroom teacher" (p. 10). Having the same opinion, Beauvois (1998) believed that the elimination of strong teacher dominance freed students to express themselves, resulting in a larger quantity and better quality of communication. This means that online interactions support not only the development of students' language skills, but also foster their interest and motivation in language learning aspects in general.

Regarding the users' willingness to communicate in English, Freiermuth and Jarrell (2006) conducted a study to explore female Japanese university students' willingness and propensity to communicate in English in small groups using both online chat and spoken English (face-to-face). They concluded that online chatting provided a more comfortable environment, enhancing students' willingness to communicate. The online chat provides another fruitful tool to enhance interaction in the target language. This indicates that online communication has multifarious facilities for learners, including learning, social, and cultural activities that prepare them for a professional life in their future career.

Recently, Wu, Yen and Marek (2011) carried out a study in the Taiwanese context in order to examine which elements of learning via videoconferencing most beneficially improve motivation, increase confidence and ability. They concluded that long-term changes in ability are best predicted by enjoyment of the learning experience. The data also suggested that even a small amount of authentic interaction in English made students more comfortable in applying their skills, more confident in what they learned, and more inspired to make global, cross-cultural connections.

Drawing upon the development of critical analysis, Northcote and Kendle (2001) postulated that participating in online learning activities such as discussing in online forums and searching for information online may give students the opportunity to acquire many practical online skills in a more incidental, informal manner. Some of these skills that would be useful for language learners are critical analysis of resources, effective online communication, and filtering and deciphering information.

Warschauer (1996) identified three common factors of student motivation provided by a technology-enhanced setting: communication, empowerment, and learning. "Communication" is represented by the finding that students liked the ability to communicate with others and to engage in real, as opposed to contrived, communicative acts. "Empowerment" describes the finding that students felt empowered in the technology environment since they felt less isolated and were less afraid to contact others. The "learning" factor describes the finding that students believed the computer gave them certain kinds of control over their learning by enabling them to learn faster and more independently and to write more creatively.

In addition to the communicative benefits of the Internet, it "has also become an unrivalled source of information and reference for work, educational and recreational purposes" (O’Dowd, 2007, p. 17). In general, it cannot be ignored that the Internet has given many opportunities and services for humanity starting with developing the different aspects of language leaning via e-learning and even entire online degree programs, and ending with other e-services such as eshopping, e-commerce, e-tickets, e-conferences, etc. 
What can be drawn from this extensive review of literature and previous studies is that online communication has experienced dramatic growth as a learning tool. It has the potential to promote learners' autonomy. In other words, it can play a critical role in helping them to develop their language, as being competent in using English successfully is a driving factor for competition at the national, regional, and international labor market. As learning English is moving from decontextualization to unspecified contexts, the opportunity to use the language with others may not be available in the classroom settings. This shift depends on the learners' motivation and their willingness to look at the shining educational side of these online means. What is required is that they should engage and exploit this means that create interactive environment for filling any gap in the classroom and competing in the marketplace. Today the studentcentered approach is popular, in which the teacher plays a facilitator role rather than a sole provider or spoon feeder of information. Hence, in support of this approach, the independent autonomous learning is prevailing in which learners are assumed to be responsible for their own learning either inside or outside classroom settings. McLoughlin and Lee (2007) stated that students today demand more autonomy, communicative skills, connectivity, interaction and socioexperiential learning opportunities in their learning contexts. Therefore, students are encouraged more than ever before to grasp every in- or out-of-class opportunity for developing their English levels.

\section{Background of the Study}

\subsection{Aims of the Study}

This study aimed at gaining a deeper understanding of the students' perceptions regarding the employment of online settings as an educational tool for developing their English. It also sought to identify which of the following factors (age, university level, foreign friendship, the frequent use of the Internet, and the frequent use of English for online communication) that may affect the students' perceptions of the role of online communication in fostering their language learning.

\subsection{Hypotheses of the Study}

First, it was hypothesized that online communication has a useful and meaningful impact on the students' development of the different aspects of language learning, including the four language skills, building new vocabulary, being selfconfident, increasing their motivation and positive attitudes towards others and their cultures, and language anxiety decrease. Second, it was postulated that the factors of age, university level, foreign friendship, the use of the Internet, and the use of English for communication may affect the students' perceptions of the role of online communication in fostering their language learning.

\subsection{Research Questions}

This study addressed the following questions:

1. How do the students perceive the role of online communication in fostering their learning of English?

2. Do the demographic, social and cultural factors influence the students' perceptions of the role of online communication on English learning?

\subsection{Research Problem and Rationale behind the Present Study}

Humans are social beings by nature; therefore, no one can deny that learning a language is tied to social interactions. As a result, there is an expanding shift from the formal in-class activities of learning the language to learning it informally out of classroom atmosphere using online settings. As it is known, online contexts can be used for achieving at least two important goals: first for social purposes, including keeping in touch with others and maintaining existing relationships, and second for educational purposes. In the Saudi context, it was observed that the most common use of the Internet is the first one in which people in general and students in particular spend more time online in informal environmentsinteracting with peers and receiving feedback on topics of a particular interest. Smart phones, for example, allow multiple ways of communicating so they are used widely and considered as a fashion. In this concern, students can give less attention to socialization process and more attention to the accessible learning aspects of this tool, or at least there should be a balance between the two. Hence, this study focused on the shining educational side of this means as it has opened good opportunities and facilities for learners to develop their language learning.

\subsection{Significance of the Study}

The importance of this study stemmed from the fact that it touched up-to-date topic and means. Additionally, some of the above-mentioned studies concentrated on the development and implementation of online courses, while there was a dearth of empirical research that addressed the importance of informal online communication outside the classroom atmosphere. As students may feel bored of the classroom setting, they can positively employ this enjoyable and easily accessible means for proficient language learning and competing effectively with others. It was anticipated that this study could make sense and constituted an important additional contribution to the available literature on informal or incidental language learning and communication. It also stressed on sensitizing learners to the useful educational side of online tools.

\section{Methodology}

\subsection{Characteristics of the Participants}

This study was conducted at University of Bisha, College of Sciences and Arts (boys), Al-Namas Campus, Saudi Arabia. Regarding the defining characteristics of the participants, they were homogeneous in terms of their gender, culture, major and aim. Specifically, all the participants were male undergraduate Saudi students of English. They joined the English major for receiving BA in English. Many demographic and personal independent variables were taken into account such as age, university level, foreign friendship, the frequent use of the Internet, and the frequent use 
of English online. The participants of this study were 171 male students from different levels. Taking into consideration the participants' university level, the Saudi educational system considers each semester a level. This means that there are eight levels during the four-year university study. Table 1 summarizes the participants' characteristics of age, university level, foreign friendship, frequent use of the Internet, and the frequent use of English online.

Table 1. The frequency and percentage of the participants' characteristics

\begin{tabular}{|c|c|c|c|}
\hline Item & Options & Frequency & Percentage \\
\hline \multirow[t]{3}{*}{ Age } & $18-20$ years old & 86 & 50.3 \\
\hline & $21-23$ years old & 81 & 47.4 \\
\hline & 24-26 years old & 4 & 2.3 \\
\hline \multirow[t]{8}{*}{ University level } & Level 1 & 29 & 17.0 \\
\hline & Level 2 & 41 & 24.0 \\
\hline & Level 3 & 15 & 8.8 \\
\hline & Level 4 & 22 & 12.9 \\
\hline & Level 5 & 17 & 9.9 \\
\hline & Level 6 & 23 & 13.5 \\
\hline & Level 7 & 7 & 4.1 \\
\hline & Level 8 & 17 & 9.9 \\
\hline \multirow[t]{2}{*}{ Foreign friendship } & Yes & 79 & 46.2 \\
\hline & No & 91 & 53.2 \\
\hline \multirow{4}{*}{$\begin{array}{l}\text { Frequent use of the } \\
\text { Internet }\end{array}$} & Always & 11 & 6.4 \\
\hline & Usually & 33 & 19.3 \\
\hline & Sometimes & 107 & 62.6 \\
\hline & Never & 19 & 11.1 \\
\hline \multirow{4}{*}{$\begin{array}{l}\text { Frequent use of English } \\
\text { online }\end{array}$} & Always & 39 & 22.8 \\
\hline & Usually & 60 & 35.1 \\
\hline & Sometimes & 51 & 29.8 \\
\hline & Rarely & 21 & 12.3 \\
\hline
\end{tabular}

\subsection{Research Instrument}

This study was quantitatively designed since it employed a questionnaire as a research instrument and the data were analyzed statistically. The written questionnaire was implemented to collect the data of the study and it was composed of two sections (see the appendix). The first section elicited the participants' demographic and personal information such as age, university level, foreign friendship, the frequent use of the Internet, and the frequent use of English online. The items of the first section were categorical. The second section included ten items, which were about the basic language skills (reading, writing, listening, and speaking) and other aspects of language learning (motivation, vocabulary building, showing respect towards others and their cultures, knowing about others' personality and their cultures, self-confidence, and worry decrease). All the items of the second section were Likert-type scale measuring from 5 (strongly agree); 4 (agree); 3 (neutral/uncertain); 2 (disagree); to 1 (strongly disagree). Regarding the variables of the study, it should be referred that online communication and the factors mentioned above were considered as independent variables that may affect the learning of English (as a dependent variable).

\subsection{Validity and Reliability of the Instrument}

To ensure the validity of the questionnaire, some experts and statistical analysts were requested to evaluate it for any comments, suggestions, addition or even deletion of any irrelevant statements. Their notes and suggestions were inserted into the questionnaire. On the other hand, Pallant (2005) refers to the internal consistency as "the degree to which the items that make up the scale are all measuring the same underlying attribute (i.e. the extent to which the items 'hang together')" (p. 6). Hence, the reliability of the ten-item scale was checked using Cronbach's alpha coefficient and it was found to be $(\alpha=.890)$ (see Table 2$)$. This denotes that the reliability of the ten likert-type scale items was very high as it was greater than $(\alpha>.7)$ as it is recommended by Nunnally (1978).

Table 2. The reliability statistics using Cronbach's alpha coefficient

\begin{tabular}{cc}
\hline Cronbach's Alpha & N of Items \\
\hline .890 & 10 \\
\hline
\end{tabular}


As an ethical procedure, an official permission was granted from the dean of the college to conduct this study. The present study was carried out during the first semester of the academic year 2015-2016. With the help of the researcher's colleagues, the printed questionnaire was administered to the participants during a usual class time. Concerning the sampling procedure, the participants were randomly chosen to voluntarily take part in this study, depending on their attendance before the first mid-term exam as they mostly attended classes for exam revision. They were given some verbal instructions on how to respond to the questionnaire and were made fully aware of the purpose of the study. They were also given enough time to fill in the questionnaire and then the questionnaire copies were immediately returned upon completion.

\subsection{Data Analysis Procedure}

After collecting the questionnaire copies from the participants, the responses were subjected to revision in order to find out if there were any incomplete or random responses. Then, the data were coded and prepared for analysis using Statistical Package for Social Sciences (SPSS) 21.0 version. Descriptive and inferential statistical techniques were employed for analyzing the data of the study. On the one hand, the descriptive statistics were used for preliminary analyses i.e. reporting the mean (M), standard deviation (SD), frequencies, and percentages of the independent and dependent variables. On the other hand, the inferential statistical analysis was run in order to discover the statistically significant differences between the independent and dependent variables of the study. In particular, independentsamples t-test was utilized for identifying if there were statistically significant differences between the independent variables of two groups and the dependent variable of the study. Similarly, the one-way analysis of variance (ANOVA) was used to find out if there were statistically significant differences between the independent variables of more than two groups and the dependent variable of the study.

\section{Results of the Study}

The results of the study were reported based on the hypotheses of the study:

The first hypothesis: Online communication has a useful and meaningful impact on the students' development of their language learning

Based on the participants' views, the researcher started with identifying whether the online communication can function as an educational environment for developing their English levels or not. The results of this scale were divided into two sections: results of the language skills and results of the other aspects of language learning. As shown in Table 3, the participants generally viewed the role of online communication as critical for developing their basic language skills (reading, writing, listening, and speaking). More specifically, the results indicated that the online communication positively affected the participants' reading and writing skills $(\mathrm{M}=4.25, \mathrm{SD}=.825)$ and their speaking and listening skills $(\mathrm{M}=4.15, \mathrm{SD}=.912)$.

With regard to the other aspects of language learning, it was obvious that online communication played an important role in boosting these aspects (see Table 3). In particular, online communication enhanced the communicators' motivation to learn English, respect towards others and their cultures, enrich their knowledge of their communication partners and their cultures, get wide vocabulary, and be more confident and less worried while communicating online with others.

Table 3. The mean and standard deviation of the online communication score

\begin{tabular}{lllc}
\hline & & & \\
& & & \\
& I think that online communication with others & & \\
\hline 1. & motivates me to learn more English. & 3.07 & .980 \\
\hline 2. & encourages me to show respect towards others. & 3.69 & .947 \\
\hline 3. & encourages me to show respect for their cultures. & 3.68 & .991 \\
\hline 4. & lets me know more about others' personality, behaviors, values, etc. & 3.75 & 1.028 \\
\hline 5. & lets me know more about others' cultures. & 3.86 & 1.014 \\
\hline 6. & helps me to develop my English speaking and listening skills. & 4.15 & .912 \\
\hline 7. & helps me to develop my English reading and writing skills. & 4.25 & .825 \\
\hline 8. & helps me to build up more English vocabulary. & 4.22 & .803 \\
\hline 9. & helps me to be self-confident when communicating in English. & 4.04 & .972 \\
\hline 10 & helps me to be less worried when communicating in English. & 3.91 & 1.048 \\
\hline & Total of the M and SD of the ten items & 3.96 & .952 \\
\hline
\end{tabular}

In light of the aforementioned results, there was a high agreement to the statements of the questionnaire. As the total mean and standard deviation of the ten-item scale was $(\mathrm{M}=3.96, \mathrm{SD}=.952)$, it was clearly notable that the majority of the participants had a high positive perception of the important and effective role of online communication in fostering their English proficiency. This included the input and output skills (reading, writing, listening, and speaking) and the other aspects that help in learning the language (motivation, attitudes, confidence, respect, vocabulary, and less worry). Supporting this point, the responses of the participants were clustered around 'strongly agree' and 'agree' options. It is noticeable that the participants showed less respect towards others and their cultures. Therefore, they should avoid such 
negative attitude towards others and their cultures bearing in mind that we are different (rather than using the good-andbad criterion) and that the similarities should be accepted and the differences appreciated. They also should be sensitized that scorning or undervaluing others and their cultures can lead to misunderstanding and conflict, and hence failure in communication process.

In general, the first hypothesis was supported in which online communication plays a crucial role in fostering the students' English levels. This could be due to the influential and widespread use of the Internet in their daily life.

The second hypothesis: The factors of age, university level, foreign friendship, the use of the Internet, and the use of English for communication may affect the students' perceptions of the role of online communication in fostering their language learning

As mentioned above, different factors (age, university level, foreign friendship, the frequent use of the Internet, and the frequent use of English online) were considered as independent variables that might affect the research outcome. They were analyzed here one at a time. To find an answer to the second question and to test the second hypothesis, two statistical techniques were used to analyze the data of the study.

The independent-samples t-test was used to identify the statistically significant differences between the total of the online communication scores for the two groups of people who have and do not have foreign friends. As shown in Table 4, it can be said that there was a significant difference (but this difference was not shown statistically) in the mean scores on the role of online communication scores in fostering and language learning for each of the two groups of people who have $(\mathrm{M}=40.1, \mathrm{SD}=5.54)$ and do not have foreign friendship with others $[\mathrm{M}=39.2, \mathrm{SD}=7.66 ; \mathrm{t}=.896$, $\mathrm{p}=.061]$.

Table 4. The significant differences of foreign friendship compared with the total of the online communication scores using t-test analysis

\begin{tabular}{lccccccc}
\hline \multicolumn{2}{c}{ Foreign friendship } & $\mathrm{N}$ & $\mathrm{M}$ & $\mathrm{SD}$ & $\mathrm{t}$ & $\mathrm{F}$ & Sig. \\
\hline \multirow{2}{*}{$\begin{array}{l}\text { The role of online } \\
\text { communication }\end{array}$} & Yes & 79 & 40.1 & 5.54 & .896 & 3.547 & $.061^{*}$ \\
\cline { 2 - 9 } & No & 90 & 39.2 & 7.66 & & &
\end{tabular}

*. The mean difference can be considered significant as $\mathrm{p}$ is near .05 .

Regarding the exploration of the impact of age variable on the role of online communication scores in developing the participants' English, a one-way analysis of variance (ANOVA) was run. Based on their age, the participants were divided into four groups (Group 1: 18-20 years; Group 2: 21-23 years; Group 3: 24-26 years; Group 4: more than 26 years). As shown in Table 5, it was found that there was no statistically significant difference at the $p>.05$ level in scores for the four age groups $[F(2,167)=.113, p=.893]$. This ensured that the four age groups did not differ significantly from each other when compared with the online communication scores.

Table 5. The significant differences of age compared with the total of the online communication scores using ANOVA analysis

\begin{tabular}{llccccc}
\multicolumn{2}{c}{ Age of the participants } & $\mathrm{N}$ & $\mathrm{M}$ & $\mathrm{SD}$ & $\mathrm{F}$ & Sig. \\
\hline \multirow{2}{*}{$\begin{array}{l}\text { The role of online } \\
\text { communication }\end{array}$} & 18-20 years old & 86 & 39.57 & 6.91 & \multirow{2}{*}{.113} & \multirow{2}{*}{.893} \\
\cline { 2 - 6 } & 21-23 years old & 80 & 39.81 & 6.80 & & \\
\cline { 2 - 5 } & 24-26 years old & 4 & 38.25 & 3.59 & & \\
\cline { 2 - 5 } & Total & 170 & 39.65 & 6.78 & &
\end{tabular}

With reference to the impact of university level on the role of online communication scores in developing the participants' English levels, ANOVA inferred that there was a statistically significant difference at the $p<.05$ level in scores for the eight levels of the participants $[F(2,162)=2.673, p=.012]$ (see Table 6). Based on the results of Post Hoc, it was disclosed that level 1 , level $2(\mathrm{p}=.020)$ and level 5 students $(\mathrm{p}=.031)$ differed significantly in terms of their perceptions of the role of online communication in developing their English levels.

Table 6. The significant differences of the participants' university level compared with the total of the online communication scores using ANOVA analysis

\begin{tabular}{|c|c|c|c|c|c|c|}
\hline \multicolumn{2}{|c|}{ The participants' different university level } & $\mathrm{N}$ & M & SD & $\mathrm{F}$ & Sig. \\
\hline \multirow{9}{*}{$\begin{array}{l}\text { The role of online } \\
\text { communication }\end{array}$} & Level 1 & 29 & 43.48 & 4.82 & \multirow[t]{9}{*}{2.673} & \multirow[t]{9}{*}{$.012 *$} \\
\hline & Level 2 & 41 & 38.10 & 6.92 & & \\
\hline & Level 3 & 15 & 37.60 & 7.09 & & \\
\hline & Level 4 & 22 & 38.59 & 7.15 & & \\
\hline & Level 5 & 16 & 36.88 & 10.16 & & \\
\hline & Level 6 & 23 & 41.00 & 4.15 & & \\
\hline & Level 7 & 7 & 41.43 & 4.72 & & \\
\hline & Level 8 & 17 & 40.12 & 5.86 & & \\
\hline & Total & 170 & 39.65 & 6.78 & & \\
\hline
\end{tabular}

*. The mean difference is significant at the 0.05 level. 
Regarding the influence of the frequent use of the Internet on the role of online communication scores in developing the participants' English levels, ANOVA explained that there was a statistically significant difference at the $p<.05$ level in scores for the four choices $[F(2,165)=3.330, p=.021]$. Post Hoc technique indicated that 'always' and 'never' choices ( $\mathrm{p}$ $=.010$ ) differed significantly in terms of their perceptions of the role of online communication in developing their English levels (see Table 7).

Table 7. The significant differences of the participants' frequent use of the Internet compared with the total of the online communication scores using ANOVA analysis

\begin{tabular}{llccccc}
\hline \multicolumn{2}{l}{ The frequent use of the Internet } & $\mathrm{N}$ & $\mathrm{M}$ & $\mathrm{SD}$ & $\mathrm{F}$ & Sig. \\
\hline \multirow{2}{*}{$\begin{array}{l}\text { The role of online } \\
\text { communication }\end{array}$} & Always & 11 & 44.55 & 5.26 & \multirow{2}{*}{3.330} & $.021 *$ \\
\cline { 2 - 5 } & Usually & 33 & 39.70 & 5.49 & \\
\cline { 2 - 5 } & Sometimes & 106 & 39.69 & 6.05 & \\
\cline { 2 - 5 } & Never & 19 & 36.58 & 11.13 & \\
\cline { 2 - 5 } & Total & 169 & 39.66 & 6.80 &
\end{tabular}

Note: $* \mathrm{p}<.05=$ The mean difference is significant at the 0.05 level.

On the subject of the impact of the frequent use of English online on the role of online communication scores in developing the participants' English levels, ANOVA made it clear that there was no statistically significant difference at the $p>.05$ level in scores for the four choices $[F(2,166)=.767, p=514]$ (see Table 8). Unexpectedly, this indicates that the four choices did not differ significantly from each other when compared with the online communication scores.

Table 8. The significant differences of the participants' frequent use of English online compared with the total of the online communication scores using ANOVA analysis

\begin{tabular}{llccccc}
\hline The frequent use of English online & $\mathrm{N}$ & $\mathrm{M}$ & $\mathrm{SD}$ & $\mathrm{F}$ & Sig. \\
\hline \multirow{2}{*}{$\begin{array}{l}\text { The role of online } \\
\text { communication }\end{array}$} & Always & 39 & 38.72 & 6.67 & .767 & 514 \\
\cline { 2 - 5 } & Usually & 60 & 40.52 & 5.47 & \\
\cline { 2 - 5 } & Sometimes & 50 & 39.06 & 7.89 & \\
\cline { 2 - 5 } & Never & 21 & 40.33 & 7.59 & \\
\cline { 2 - 5 } & Total & 170 & 39.65 & 6.78 \\
\hline
\end{tabular}

To summarize this section, in support of the first hypothesis, the overall results of the study suggested that the participants generally perceived that the online communication tools could play an influential role in fostering their English levels including the basic language skills and the other aspects of language learning. Moreover, the results partially supported the second hypothesis of the study. On the one hand, it was reported that there were statistically significant differences between the three variables (the foreign friendship, university level, and the frequent use of the Internet) when comparing them with the role of online communication scores in developing the participants' English levels. On the other hand, it was found that there were no statistically significant differences between the two variables (age and the frequent use of English online) when comparing them with the role of online communication scores in developing the participants' English levels.

\section{Discussion of the Results}

The main aim of this study was to identify the perceptions and views of the participants about the role of online communication in improving their English levels, including the basic English skills and the other aspects of language learning. At this point, the results were evaluated and discussed based on their implications, especially with respect to the two hypotheses of the study.

Based on the participants' views, it was found that the first research hypothesis was supported in which online communication could play a fundamental role for effective and successful learning of English language especially in the sense of developing the four language skills and other aspects of language learning as well. This goes in line with the previous studies mentioned above which showed that online communication, if employed positively, can play an influential role in fostering language learning (Kabilan, Ahmad \& Zainol Abidin, 2010; Kern, Ware \& Warschauer, 2004; Lee, 2002; O’Dowd, 2007).

With regard to the other factors that lead to the enhancement of language learning, the results revealed that communicating online with others helps in the development of language learning. This positive view could be explained by the fact that the different online tools are easily accessible and that most of the people use them most of the time. These tools provide people with authentic interaction with people from different cultures that might not be available in face-to-face interaction. The Internet has made everything at hand in which it is possible to get any service or help online and by one click while we are at home.

In addition to the development of the learners' language skills, the online communication definitely leads to enhancing the communication parties' motivation to learn English, respecting others and their cultures, enriching their knowledge of other partners and their cultures, getting more vocabulary, and being more confident and less worried while 
communicating online. This is consistent with the previous studies mentioned in the section of the literature review (Freiermuth \& Jarrell, 2006; Kabilan, Ahmad \& Zainol Abidin, 2010; O’Dowd, 2007; Swaffar, 1998; Warschauer, 1996; Wu, Yen \& Marek, 2011; Zeiss \& Isabelli-Garcia, 2005). This might be because the learners want to complement the in-class learning and broaden their minds with more information and knowledge. It gives a good chance for learning the language freely beyond the classroom environments and without the attendance of the teacher. As stated before, the online communication is also appropriate for shy students and those who worry at the teachers' corrections of their mistakes in front of their friends and mates.

As mentioned above, the second research hypothesis was partially supported. On the one hand, the results reported that there were statistically significant differences between the three variables of the foreign friendship, university level, and the frequent use of the Internet when comparing them with the role of online communication scores in developing the participants' English levels. This might be because people who have foreign friendship are willing to use the Internet for communicating with their friends, and this friendship might be built through these online communication tools. They encourage them to use the language, be more confident and less worried at using the language or making mistakes. Foreign friendship also opens the door for communication partners to know about each other and their cultures and to respect others and their cultures. Without doubt, the university level plays a role in the participants' perceptions, as students in advanced levels might be more willing and motivated to use such tools for educational purposes. In addition, the more people use the Internet, the more they learn and master the language.

On the other hand, the results uncovered that there were no statistically significant differences between the two variables of age and the frequent use of English online when comparing them with the role of online communication scores in developing the participants' English levels. Unlike other countries, the Saudi students are allowed to enroll the university directly after their completion of the high school degree. This means that they might be at the same age or near when they enroll the university. This might be why the age does not make sense in this study. On the other hand, the use of English online was not important with regard to the participants of this study. This might be due to the other aspects of language learning, and they might use Arabic for communicating with their friends.

To sum up, it can be stated that the results of this study are helpful in the sense that they sensitize and raise the learners' awareness to the importance of using the online communication tools positively for educational purposes. For the generalizability of the results, deeper research needs to be conducted in different campuses at the University of Bisha and at other Saudi universities, if possible.

\section{Findings}

On the basis of the data discussed above, the findings of the study can be summarized as follows:

I. Based on the beliefs of the participants, the online communication tools can be employed to develop the English levels including the four language skills and the other aspects of language learning. The aspects of language learning include the enhancement of the communication parties' motivation to learn English, respect towards others and their cultures, gaining more knowledge of their partners and their cultures, getting more vocabulary, being more confident and less worried while communicating online with others.

II. There were statistically significant differences between the three variables of the foreign friendship, university level, and the frequent use of the Internet when comparing them with the role of online communication scores in developing the participants' English levels.

III. There were no statistically significant differences between the two variables of age and the frequent use of English online when comparing them with the role of online communication scores in developing the participants' English levels.

\section{Conclusion}

As English has been well recognized as being an essential language for international communication, learning it is no longer solely confined to the classroom environment. Rather, it can also be acquired from other sources beyond the classroom boundaries; online communication tools are but one of them. This study strived to shed more light on fostering the students' English levels through the lens of online communication tools. Consequently, it is believed that much can be learned from the online settings since everything is at the hand of the foreign language learners, and they no longer need to leave their homes, travel to meet people from other countries, and learn the language and its culture. Rather, by one click, one can achieve the required needs online.

As there is an urgent need of English language in different situations and occasions, it is a joint responsibility of the teachers, policy makers, and parents as well to double their efforts and draw the students' attention to the effective use of the online communication tools for real educational purposes. It is also recommended that students should value this tool and employ it for more educational than personal or social objectives or at least there should be a balance. It is hoped that the use of new technologies will in some way bring about more progressive and innovative approaches to language learning. O'Dowd (2007) suggested that "the younger generation of language learners will be particularly prepared and suited for online language learning due to their regular use of new technologies for recreational and social purposes" (p. 19). Hereafter, learners can be convinced that the informal online communication complements the formal in-class lessons and activities, and it has a shining educational role in helping them to develop the different aspects of language learning. For being highly qualified learners, they should take advantage of such tools and consider them as educational tools for better learning. 
References

Beauvois, M. (1998). Conversations in slow motion: Computer-mediated communication in the foreign language classroom. The Canadian Modern Language Review, 54(2), 198-217. DOI: http://dx.doi.org/10.3138/cmlr.54.2.198

Cassell, J., \& Tversky, D. (2005). The language of online intercultural community formation. Journal of ComputerMediated Communication, 10(2), 1-22. DOI: 10.1111/j.1083-6101.2005.tb00239.x

Chapelle, C. A. (2003). English language learning and technology: Lectures on applied linguistics in the age of information and communication technology. Amsterdam: John Benjamins Publishing Company.

Freiermuth, M., \& Jarrell, D. (2006). Willingness to communicate: Can online chat help? International Journal of Applied Linguistics, 16(2), 189-212. DOI: 10.1111/j.1473-4192.2006.00113.x

Kabilan, M. K., Ahmad, N., \& Zainol Abidin, M. J. (2010). Facebook: An online environment for learning of English in institutions of higher education. The Internet and Higher Education, 13(4), 179-187. doi:10.1016/j.iheduc.2010.07.003

Kern, R., Ware, P., \& Warschauer, M. (2004). Crossing frontiers: New directions in online pedagogy and research. Annual Review of Applied Linguistics, 24, 243-260. DOI: 10.1017/S0267190504000091

O’Dowd, R. (Ed.). (2007). Online intercultural exchange: An introduction for foreign language teachers. Clevedon: Multilingual Matters LTD.

Lee, L. (2002). Enhancing learners' communication skills through synchronous electronic interaction and task-based instruction. Foreign Language Annals, 35(1), 16-24. Retrieved from http://citeseerx.ist.psu.edu/viewdoc/download?doi=10.1.1.477.1543\&rep=rep1\&type=pdf

Liu, F., Chen, M. C., Sun, Y. S., Wible, D., \& Kuo, C. (2010). Extending the TAM model to explore the factors that affect intention to use an online learning community. Computers \& Education, 54(2), 600-610. doi:10.1016/j.compedu.2009.09.009

Meier, C. (2007). Enhancing intercultural understanding using E-learning strategies. South African Journal of Education, 27, 655-671. Retrieved from http://www.ajol.info/index.php/saje/article/viewFile/25138/4337

Northcote, M. T., \& Kendle, A. (2001, December). Informal online networks for learning: Making use of incidental learning through recreation. Education Conference Papers. Paper 31. Retrieved from http://research.avondale.edu.au/edu_conferences/31

Nunnally, J. O. (1978). Psychometric theory. New York, NY: McGraw-Hill.

Pallant, J. (2005). SPSS survival manual: A step by step guide to data analysis using SPSS for Windows (Version 12)

( $2^{\text {nd }}$ ed.). Australia: Allen \& Unwin.

Pasfield-Neofitou, S. (2012). Online communication in a second language: Social interaction, language use, and learning Japanese. Bristol: Multilingual Matters.

Salmon, G. (2011). E-moderating: The key to teaching and learning online (3 ${ }^{\text {rd }}$ Ed.). New York: Routledge.

Singhal, M. (1998). Computer Mediated Communication (CMC): Technology for enhancing foreign language/culture education. On-Call, 12(1), 10-15. Retrieved from http://www.aulibrary.au.edu/multim1/ABAC_Pub/The-EnglishTeacher-An-International-Journal/v2-n3-4.pdf

Stepp-Greany, J. (2002). Student perceptions on language learning in a technological environment: Implications for the new millennium. Language Learning \& Technology, 6(1), 165-180. Retrieved from http://citeseerx.ist.psu.edu/viewdoc/download?doi=10.1.1.563.810\&rep=rep1\&type=pdf

Ware, P. D., \& Kramsch, C. (2005). Toward an intercultural stance: Teaching German and English through telecollaboration. The Modern Language Journal, 89(2), 190-205. Retrieved from http://blogs.cornell.edu/portfolio/files/2010/01/WareKramsch-

TowardanInterculturalStanceTeachingGermanandEnglishthroughTelecollaboration1.pdf

Warschauer, M. (1996). Motivational aspects of using computers for writing and communication. In M. Warschauer (Ed.), Telecollaboration in foreign language learning: Proceedings of the Hawai'I Symposium (Technical Report \# 12; pp. 29-46). Honolulu: University of Hawai'i.

Warschauer, M. (2004). Comparing face-to-face and electronic discussion in the second language classroom. CALICO

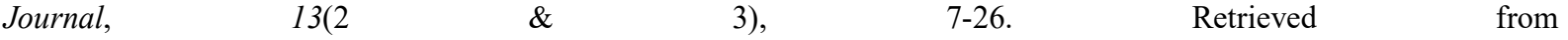
https://journals.equinoxpub.com/index.php/CALICO/article/viewFile/23397/19402

Wu, W. V., Yen, L. L., \& Marek, M. (2011). Using online EFL interaction to increase confidence, motivation, and ability. Educational Technology \& Society, 14(3), 118-129. Retrieved from http://www.anitacrawley.net/Articles/Wenchi.pdf

Yang, S. C., \& Chen, J. J. (2014). Fostering foreign language learning through technology-enhanced intercultural projects. Language Learning \& Technology, 18(1), 57-75. Retrieved from http://1lt.msu.edu/issues/february2014/yangchen.pdf

Zeiss, E., \& Isabelli-Garcia, C. L. (2005). The role of asynchronous computer mediated communication on enhancing cultural awareness. Computer Assisted Language Learning, 18(3), 151-169. DOI: 10.1080/09588220500173310. 
Dear participants,

The researcher is conducting a study entitled "The Impact of Online Communication on Learning English: A

Case Study of Saudi EFL Learners". You are cordially invited to answer this questionnaire. Your answers will be kept secret and used only for academic purpose. Please put a tick $(\sqrt{ })$ next to the appropriate response.

\section{SECTION I: Personal Information}

1. Age: $\square 18-20$ years $\square 21-23$ years $\square 24-26$ years $\square$ more than 26 years

2. University level: $\square 1 \quad \square 2 \quad \square 3 \quad \square 4 \quad \square 5 \quad \square 6 \quad \square 7 \quad \square 8$

3. I have friends from other cultures. $\square$ Yes $\square$ No

4. I .......... have access to the Internet. 口always 口usually
口sometimes
$\square$ never

5. I .......... use English while communicating online with others.
口always
cusually
口sometimes
$\square$ never

\section{SECTION II: Online communication with others}

\begin{tabular}{|c|c|c|c|c|c|c|}
\hline & I think that online communication with others & 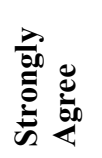 & 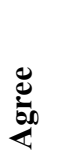 & 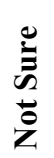 & 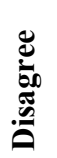 & 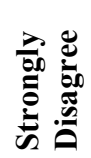 \\
\hline 1 & motivates me to learn more English. & & & & & \\
\hline 2 & encourages me to show respect towards others. & & & & & \\
\hline 3 & encourages me to show respect for their cultures. & & & & & \\
\hline 4 & $\begin{array}{l}\text { lets me know more about others' personality, behaviors, } \\
\text { values, etc. }\end{array}$ & & & & & \\
\hline 5 & lets me know more about others' cultures. & & & & & \\
\hline 6 & helps me to develop my English speaking and listening skills. & & & & & \\
\hline 7 & helps me to develop my English reading and writing skills. & & & & & \\
\hline 8 & helps me to build up more English vocabulary. & & & & & \\
\hline 9 & $\begin{array}{l}\text { helps me to be self-confident when communicating in } \\
\text { English. }\end{array}$ & & & & & \\
\hline 10 & helps me to be less worried when communicating in English. & & & & & \\
\hline
\end{tabular}

